\title{
The need of the change of the conceptualisation of hydrologic processes under extreme conditions - taking reference evapotranspiration as an example
}

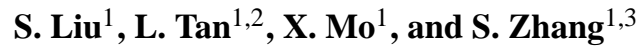 \\ ${ }^{1}$ Key Laboratory of Water Cycle and Related Land Surface Processes, Institute of Geographic Sciences and \\ Natural Resources Research (IGSNRR), Chinese Academy of Science (CAS), Beijing, 100101, China \\ ${ }^{2}$ University of Chinese Academy of Sciences, Beijing, 100049, China \\ ${ }^{3}$ Beijing Forestry University, School of Soil \& Water Conservation, Beijing, 100083, China
}

Correspondence to: S. Liu (liusx@igsnrr.ac.cn)

Received: 12 March 2015 - Accepted: 12 March 2015 - Published: 12 June 2015

\begin{abstract}
What a hydrological model displays is the relationships between the output and input in daily, monthly, yearly and other temporal scales. In the case of climate change or other environment changes, the input of the hydrological model may show a gradual or abrupt change. There have been numerous documented studies to explore the response of output of the hydrological models to the change of the input with scenario simulation. Most of the studies assumed that the conceptualisation of hydrologic processes will remain, which may be true for the gradual change of the input. However, under extreme conditions the conceptualisation of hydrologic processes may be completely changed. Taking an example of the Allen's formula to calculate crop reference evapotranspiration $\left(\mathrm{ET}_{0}\right)$ as a simple hydrological model, we analyze the alternation of the extreme in $\mathrm{ET}_{0}$ from 1955 to 2012 at the Chongling Experimental Station located in Hebei Province, China. The relationships between $\mathrm{ET}_{0}$ and the meteorological factors for the average values, minimum (maximum) values at daily, monthly and annual scales are revealed. It is found the extreme of the output can follow the extreme of the input better when their relationship is more linear. For non-liner relationship, the extreme of the input cannot at all be reflected from the extreme of the output. Relatively, extreme event at daily scale is harder to be shown than that at monthly scale. The result implicates that a routine model may not be able to catch the response to extreme events and it is even more so as we extrapolate models to higher temperature/ $\mathrm{CO}_{2}$ conditions in the future. Some possible choices for the improvements are suggested for predicting hydrological extremes.
\end{abstract}

\section{Introduction}

Hydrological models are the relationships between hydrological signatures and their driving variables and the conceptualisation/understanding of the two. As summarized by Blöschl et al. (2013), hydrological signatures include annual runoff, seasonal runoff, low flow, floods, flow duration curve, hydrograph and process understanding. From the view of hydrological cycle, they shall also cover the average, seasonal pattern, minimum, maximum, flow duration curve and evolution change of all other hydrological elements besides runoff.

Hydrological models are usually used to explore the changes in hydrological signatures. Under the context of changes in both climate and environment, hydrological models are also used to explore the responses of outputs to the changes of inputs, including the extreme changes which were found more and more popular as the more important features of the change (IPCC, 2013). It is recognized that the extreme of A will cause the extreme of B if the relationship between them is linear. However, if it is a nonlinear or changing relationship, it may be hard to catch the footprint of the extreme of B from the extreme of A. To testify this, a popular way is to compare the simulated values of a hydrological signature from a hydrological model with the observed ones. If it is found that the simulation results match well with the observations in all values other than the extreme ones, then a 


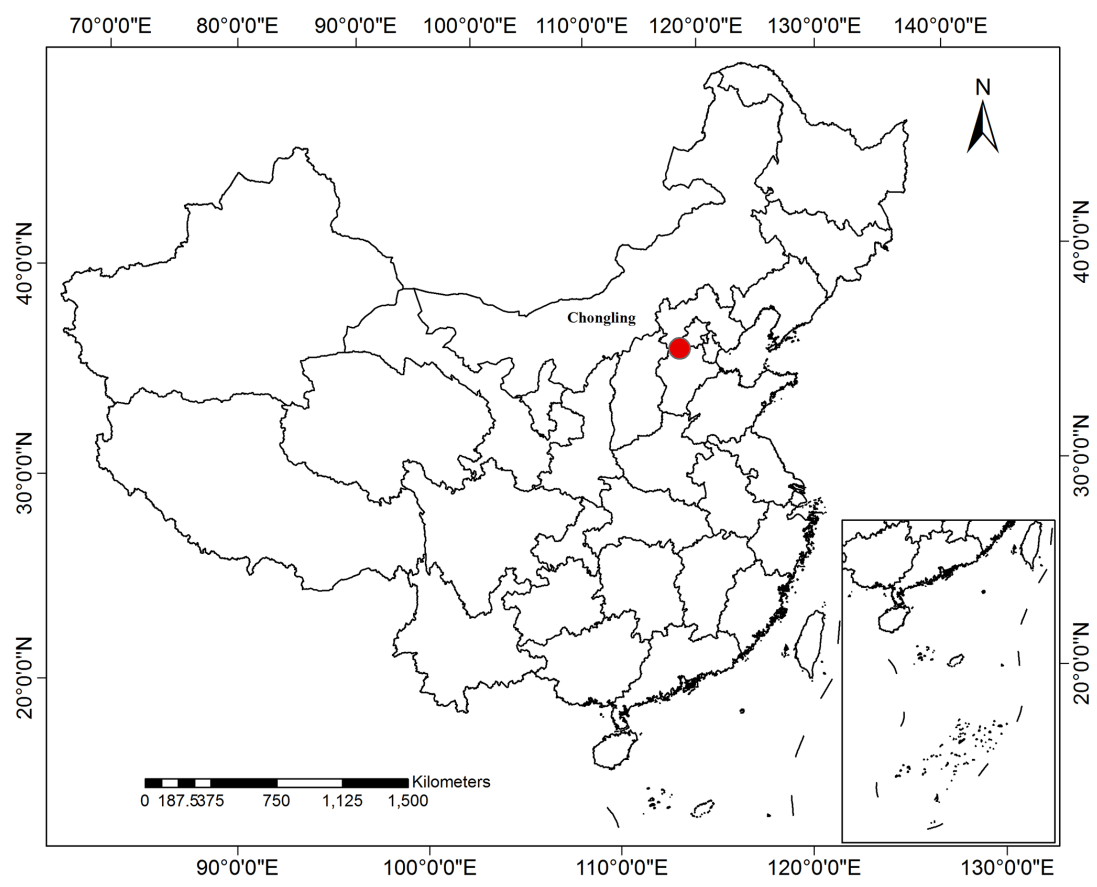

Figure 1. The study area: the Chongling Basin in China.

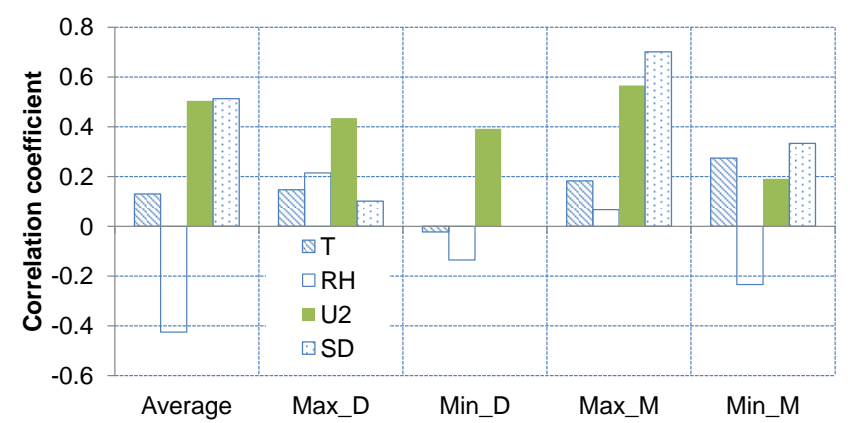

Figure 2. The correlation coefficients between $\mathrm{ET}_{0}$ and meteorological variables of $T, \mathrm{RH}, U_{2}$ and SD (average: annual average; Max_D and Min_D: the maximum and minimum among 365/366 daily values per year; Max_M and Min_M: the maximum and minimum among 12 monthly values per year).

conclusion that can be drawn from this comparison is that the conceptualisation of hydrologic processes utilized in the hydrological model remains true for the gradual change of the inputs, but under extreme conditions, most difficultly when it is outside the bounds of observed history, this conceptualisation of hydrologic processes may need to be improved.

In this article, a synthetic experiment is designed to further testify the need for the change of the conceptualisation of hydrologic processes under extreme conditions. The Allen's formula of crop reference evapotranspiration $\left(\mathrm{ET}_{0}\right)$ is taken as an example of hydrological models with perfect model structure and no parameter value input requirement. By calculating the long-term variation of $\mathrm{ET}_{0}$ from 1955 to
2012 in the Chongling Experimental Station located in Hebei Province, China, the comparison is made between the extreme of $\mathrm{ET}_{0}$ and extreme of the meteorological factors at daily, monthly and annual scales, respectively. As there is no error on model structure or caused by inaccurate parameter values, any difference will only be from the different relationships between $\mathrm{ET}_{0}$ and the meteorological variables and the role of the variables. The aim is to provide suggestions for the prediction of the extremes of hydrological signatures.

\section{Methodology}

\subsection{Study area}

The Chongling Watershed $\left(39^{\circ} 20^{\prime} 54 \mathrm{~N}-115^{\circ} 29^{\prime} 29 \mathrm{E}\right.$, Fig. 1) covers an area of $6 \mathrm{~km}^{2}$. Temperate continental monsoon climate is prevailing. The annual average temperature is $11.6^{\circ} \mathrm{C}$, and the annual average rainfall is $641 \mathrm{~mm}$ with about $76.6 \%$ of it falling during the period from July to September. Common types of vegetation in the basin include trees (e.g. Pinustabulaeformis, Biota orientalis, Robinia pseudoacacia Linn.), bushes and grasses.

\subsection{Data}

Meteorological data of Baoding station near the Chongling basin are collected and analyzed in this study. The data include daily maximum, average, and minimum temperature, precipitation, relative humidity, wind speed and sunshine duration from 1955 to 2012. 


\subsection{Methods}

\subsubsection{Allen's ET formula}

$\mathrm{ET}_{0}$ is calculated using the modified Pemman-Monteith FAO-56 equation (Allen et al., 1998):

$\mathrm{ET}_{0}=\frac{0.408 \Delta\left(R_{\mathrm{n}}-G\right)+\gamma \frac{900}{T+273} U_{2}\left(e_{\mathrm{s}}-e_{\mathrm{a}}\right)}{\Delta+\gamma\left(1+0.34 U_{2}\right)}$

where $\mathrm{ET}_{0}$ is the reference evapotranspiration $\left(\mathrm{mm} \mathrm{d}^{-1}\right) ; R_{\mathrm{n}}$ is the net radiation at land surface $\left(\mathrm{MJ} \mathrm{m}^{-2} \mathrm{~d}^{-1}\right)$ which is calculated based on sunshine duration (SD); $G$ is the soil heat flux density $\left(\mathrm{MJ} \mathrm{m}^{-2} \mathrm{~d}^{-1}\right) ; \gamma$ is the psychrometric constant $\left(\mathrm{kPa}^{\circ} \mathrm{C}^{-1}\right) ; U_{2}$ is the wind speed at a $2 \mathrm{~m}$ height $\left(\mathrm{m} \mathrm{s}^{-1}\right)$; $\Delta$ is the slope of vapor pressure versus temperature curve at air temperature $T\left(\mathrm{kPa}^{\circ} \mathrm{C}^{-1}\right) ; e_{\mathrm{s}}$ is the saturation vapor pressure at $T(\mathrm{kPa}) ; e_{\mathrm{a}}$ is the actual vapor pressure $(\mathrm{kPa})$. $\left(e_{\mathrm{s}}-e_{\mathrm{a}}\right)$ is the saturation vapor pressure deficit $(\mathrm{kPa})$, which is related with relative humidity (RH). Detailed information of this equation and its variables can be found in Allen et al. (1998).

\subsubsection{Contribution rate}

In order to calculate the contribution rate of meterological variables to $\mathrm{ET}_{0}$, the multiple regression relationship is established as:

$Y_{\mathrm{s}}=a_{1} X_{1 \mathrm{~s}}+a_{2} X_{2 \mathrm{~s}}+a_{3} X_{3 \mathrm{~s}} \ldots$

where $Y_{\mathrm{s}}$ is standardized dependent variable (e.g. $\left.\mathrm{ET}_{0}\right) ; X_{1 \mathrm{~s}}$, $X_{2 \mathrm{~s}}, X_{3 \mathrm{~s}} \ldots$ are standardized independent variables (e.g. $T$, $\left.\mathrm{SD}, \mathrm{RH}, U_{2}\right) ; a_{i}$ is the regression coefficients of the $i$ th standardized data series. $Z$-score method (Liu et al., 2008) is used for the standardization. The significant levels of the independent variables into and out of multiple regression model were set to be 0.05 and 0.1 , respectively. The relative contribution rate of the $i$ th variable, $\eta_{i}$ (Zhang et al., 2010) is,

$\eta_{i}=\frac{\left|a_{i}\right|}{\left|a_{1}\right|+\left|a_{2}\right|+\left|a_{3}\right|+\ldots}$.

The actual contribution rate, $\lambda_{i}$ is:

$\lambda_{i}=\frac{a_{i} \Delta X_{i \mathrm{~s}}}{\Delta Y_{\mathrm{s}}}$

where $\Delta X_{i}$ and $\Delta Y$ are the changes of meteorological variables and $\mathrm{ET}_{0}$, respectively, which are calculated as the differences between the average value before and after the turning point identified by using Mann-Kendall (M-K) test.

\section{Results and discussions}

3.1 The relationship between the extreme values of $\mathrm{ET}_{0}$ and the extreme values of meteorological variables

By comparing the Pearson correlation coefficients between $\mathrm{ET}_{0}$ and meteorological variables (Fig. 2), it is found that the annual average $\mathrm{ET}_{0}$ is positively correlated with $T, U_{2}$ and $\mathrm{SD}$ and negatively correlated with RH. Obviously this pattern cannot be fully reproduced by the corresponding extremes at either daily or monthly scale and for either maximum or minimum value. Relatively, the minimum reproduces the picture of average values better than the maximum. Extremes at monthly scale can reproduce the picture of average values better than at daily scale. Among the four variables, the annual average picture of $U_{2}$ and SD can be reproduced by both maximum and minimum values at both daily and monthly scales. Averagely, the month when the peak within a year of any of the four variables appears is not the same as that for $\mathrm{ET}_{0}$ (Fig. 3). These results indicate that it is not reliable to use the extremes of the input to linearly determine the extreme of the output. If it has to be done in a linear way, to determine a minimum value of the output at monthly scale is safer than to determine its maximum value at daily scale.

\subsection{The relationship between the occurrence of the extreme values of $\mathrm{ET}_{0}$ and the occurrence of the extreme values of meteorological variables}

Generally it can be seen from Fig. 4 that for variable SD there is a good relationship between the occurrence of its maximum and occurrence of the maximum of $\mathrm{ET}_{0}$ at monthly scale. For all other cases none of the occurrence of driving forces' extreme fully matches the occurrence of $\mathrm{ET}_{0}$. For some variable, such as $U_{2}$, the good relationship which is shown in the quantity's correlation coefficient (Fig. 2) at both daily and monthly scales cannot be seen from occurrence. Such an inconsistence poses a bigger challenge for the model to predict extreme of $\mathrm{ET}_{0}$ from the extreme of the driving variables.

\subsection{The context of extrapolating to a future of higher temperature/ $\mathrm{CO}_{2}$}

The above situation remains or becomes worse in the future of higher $T$ or $\mathrm{CO}_{2}$. For the model of $\mathrm{ET}_{0}$, the reference surface was assumed as an extensive surface of green, well-watered grass of uniform height, actively growing and completely shading the ground with a fixed surface resistance of $70 \mathrm{~s} \mathrm{~m}^{-1}$ implying a moderately dry soil surface resulting from about a weekly irrigation frequency (Allen et al., 1998). In the future of higher $\mathrm{CO}_{2}$ the model (Eq. 1) cannot work, which will not be discussed further here.

In the future, if daily temperature is increasing uniformly, for example increasing $2{ }^{\circ} \mathrm{C}$ daily, there will be no difference of the response of $\mathrm{ET}_{0}$ extremes as shown in Fig. 5 and the inconsistence cases remain. If the historic maximum/minimum temperature increases or decreases further, as shown in Fig. 6, there is still no direct response of $\mathrm{ET}_{0}$ extreme to the temperature extreme until the temperature's increase is totally outside of rational range of the expectance. 

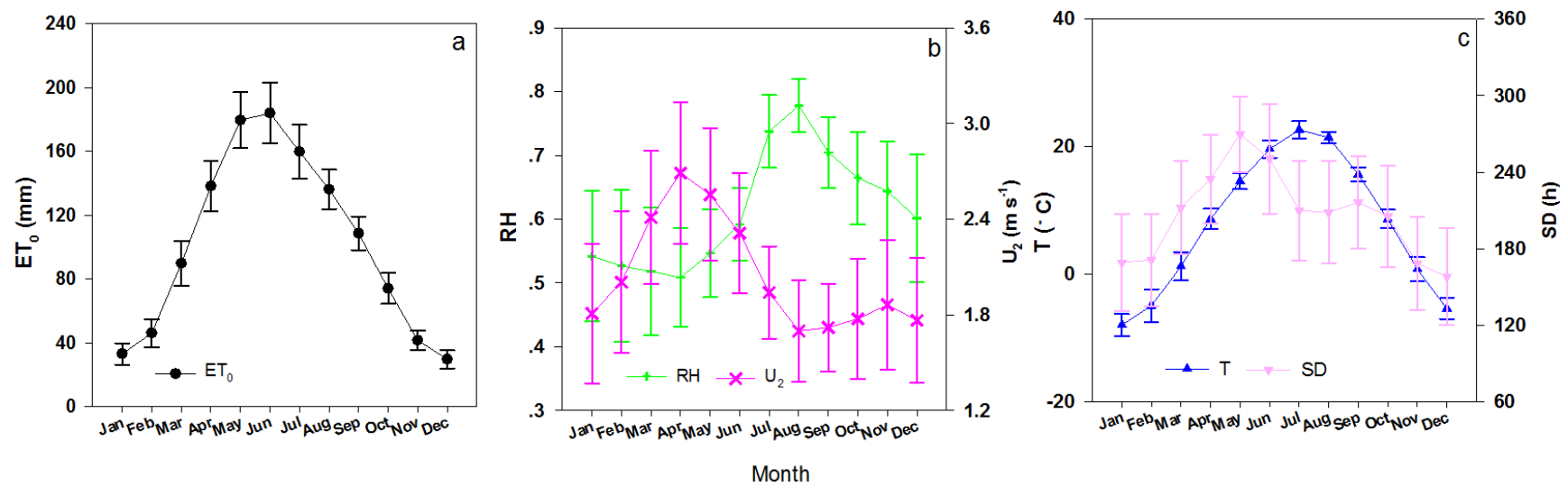

Figure 3. The seasonal pattern of $\mathrm{ET}_{0}$ and meteorological variables of $T, \mathrm{RH}, U_{2}$ and $\mathrm{SD}$ with one standard deviation.
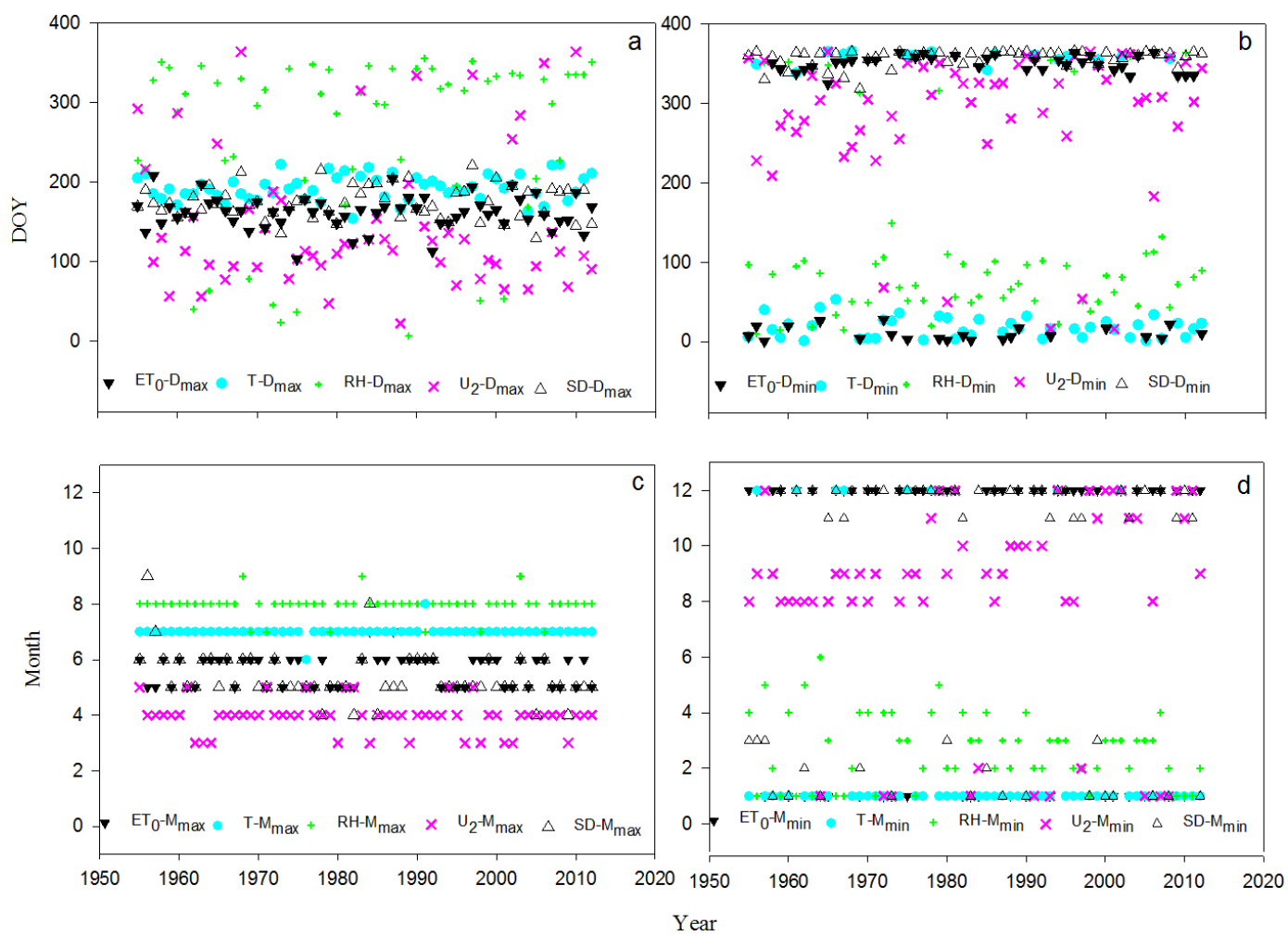

Figure 4. The occurrence of the maximum (left panels) and the minimum (right panels) of $\mathrm{ET}_{0}$ and meteorological variables at daily (upper panels) and monthly (lower panels) scale.

With the extreme events occurring more and more frequently, the situation becomes worse.

\subsection{The possible choices for the improvements}

Faced to the above difficulty, the key solution is of course to design some new conceptualisation schemes of hydrologic processes for predicting hydrological extremes which will be our future work. Finding the main driving factors of the target variable and using them in the prediction of its extreme values are also helpful. From Fig. 7, the temporal evolution pattern of $\mathrm{ET}_{0}$ is similar to those of $U_{2}$ and $\mathrm{SD}$, which can better predict the extreme of $\mathrm{ET}_{0}$ than $\mathrm{RH}$ and $T$. They also have higher correlation coefficients with $\mathrm{ET}_{0}$ in some cases (Fig. 2). It can be seen from Table 1 that the relative contribution rate of $U_{2}$ to the change of $\mathrm{ET}_{0}$ is the highest, about $33 \%$. The relative contribution rate of SD is about $24 \%$. This implies that more reliable results can be obtained if the main drivers $\left(U_{2}\right.$ and $\left.\mathrm{SD}\right)$ of the $\mathrm{ET}_{0}$ are chosen in the prediction of the extreme of $\mathrm{ET}_{0}$. The actual contribution to this from 

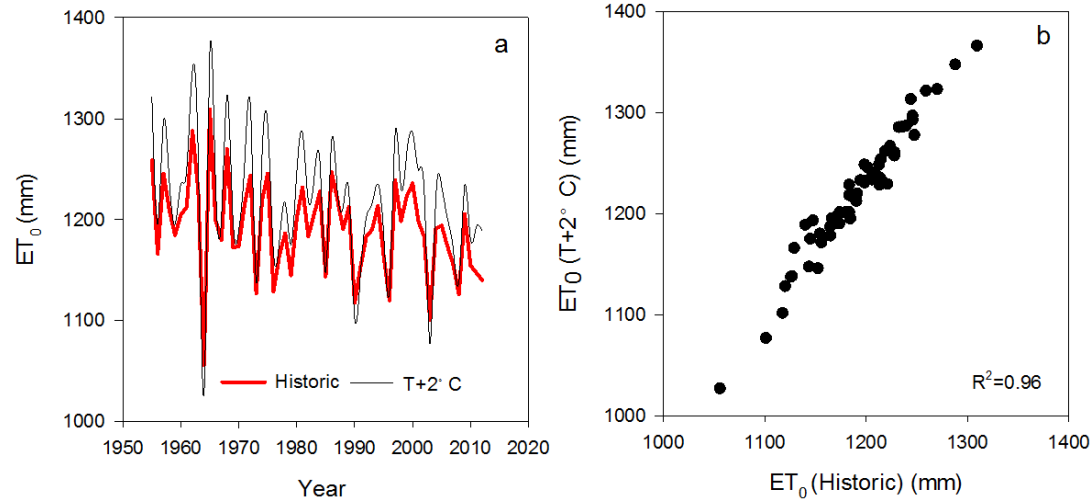

Figure 5. The comparison of $\mathrm{ET}_{0}$ under historic and changing climate conditions with daily temperature increase of $+2{ }^{\circ} \mathrm{C}$.
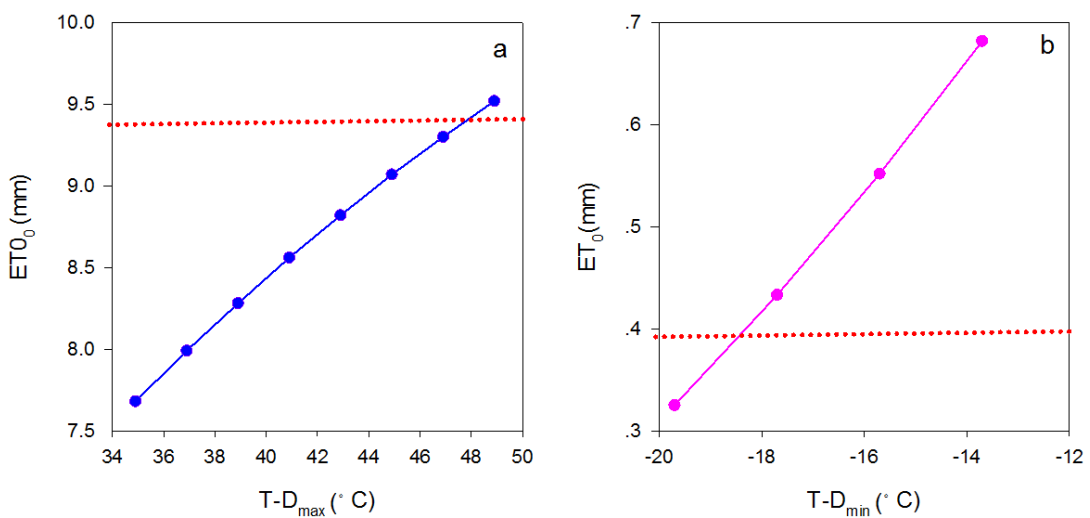

Figure 6. The variations of the (a)maximum and (b) minimum value of $\mathrm{ET}_{0}$ by assigning a continuous increase/decrease of the temperature with a $2{ }^{\circ} \mathrm{C}$ interval based on the historic maximum/minimum temperature (daily scale, $T-D_{\max } / T-D_{\min }$ ) at $24 \mathrm{July} 1955$ and 15 January 1958, respectively. The horizontal dash line represents the historic maximum/minimum value of $\mathrm{ET}_{0}$ in the respective year.

Table 1. Contribution rate of meteorological variables to the change of $\mathrm{ET}_{0}$ ("O" represents original data. "S" represents the standardized data. 1995 is the turning point identified by M-K test).

\begin{tabular}{lrrrrr}
\hline & $\begin{array}{r}\mathrm{ET}_{0} \\
(\mathrm{~mm})\end{array}$ & $\begin{array}{r}T \\
\left({ }^{\circ} \mathrm{C}\right)\end{array}$ & $\begin{array}{r}\mathrm{SD} \\
(\mathrm{h})\end{array}$ & $\begin{array}{r}\mathrm{RH} \\
(\%)\end{array}$ & $\begin{array}{r}U_{2} \\
\left(\mathrm{~m} \mathrm{~s}^{-1}\right)\end{array}$ \\
\hline Average1955-1995_O & 1227.18 & 12.57 & 7.15 & 0.62 & 2.12 \\
Average1996-2012_O & 1206.84 & 13.57 & 6.02 & 0.59 & 1.86 \\
Change_O & -20.34 & 1.00 & -1.13 & -0.04 & -0.26 \\
Average1955-1994_S & 0.09 & -0.39 & 0.47 & 0.28 & 0.25 \\
Average1995-2012_S & -0.23 & 0.94 & -1.13 & -0.67 & -0.60 \\
Change_S & -0.32 & 1.33 & -1.59 & -0.95 & -0.85 \\
Regression coefficients & & 0.45 & 0.51 & -0.47 & 0.70 \\
Relative contribution rate $(\%)$ & & 21 & 24 & 22 & 33 \\
Actual contribution rate $(\%)$ & & -186 & 252 & -140 & 186 \\
\hline
\end{tabular}

some drivers, such as $T$ and $\mathrm{RH}$, is negative (opposite to the normal driving paths) while that from other drivers, such as $U_{2}$ and $\mathrm{SD}$, is positive. The positive contribution is offset by the negative contribution, from which $\mathrm{ET}_{0}$ is decreasing over the 58 years (Table 1) with SD as a primary driving factor.
Equation (1) indicates that the relationships between $\mathrm{ET}_{0}$ and $T$ and between $\mathrm{ET}_{0}$ and $\mathrm{RH}$ are highly non-linear, those between $\mathrm{SD}$ and $\mathrm{ET}_{0}$ and between $U_{2}$ and $\mathrm{ET}_{0}$ are close to linear. The more linear the relationship between the input and output is, the easier and more accurately the input can be used to predict the footprint of hydrological signatures. 

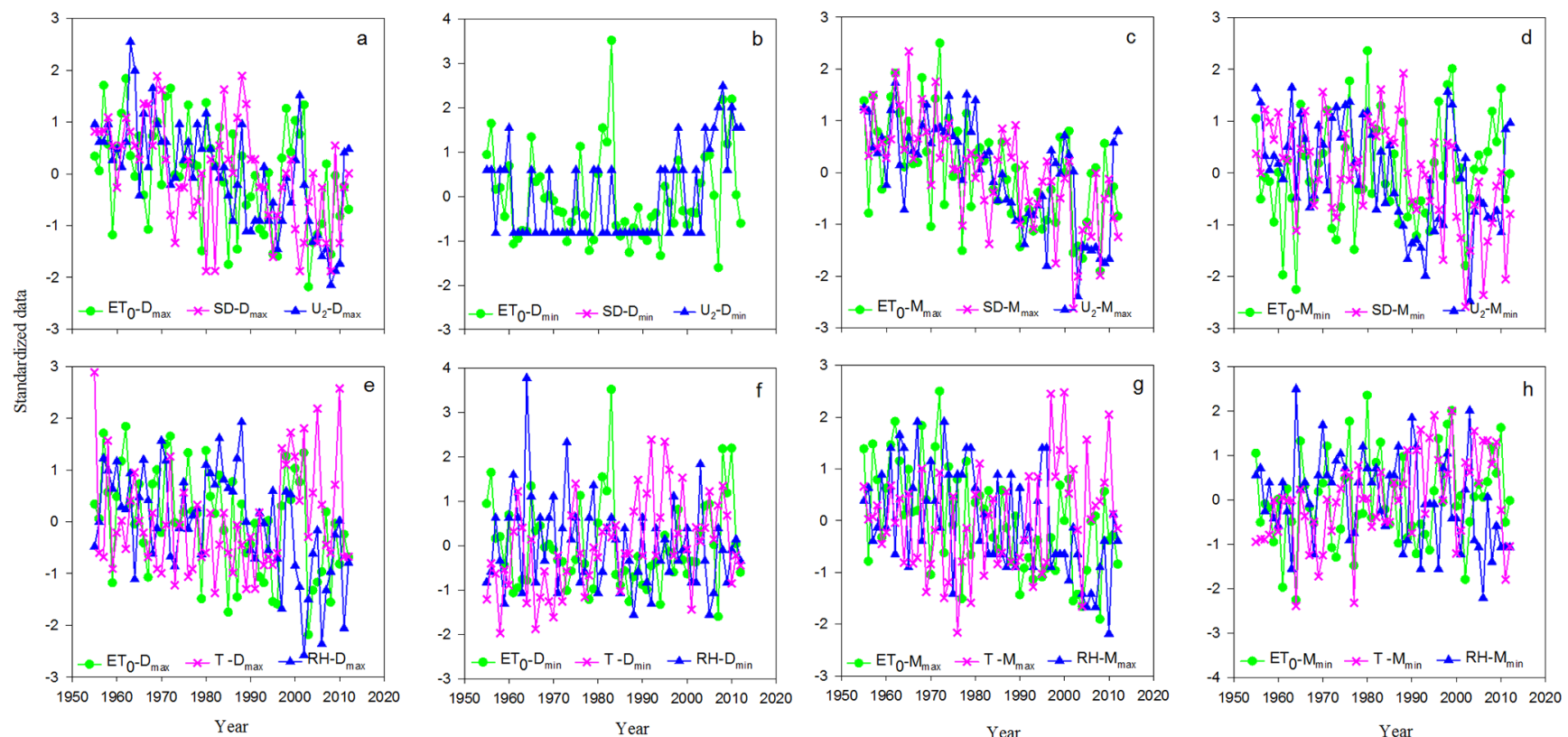

Figure 7. The evolution pattern of the extreme value of $\mathrm{ET}_{0}$ and meteorological variables at daily scale (left two column panels) and monthly scales (right two column panels).

\section{Conclusions}

By taking Allen's formula as an example of hydrological models, the relationships between the extreme (minimum and maximum) of drivers ( $T, \mathrm{SD}, \mathrm{RH}$ and $U_{2}$ ) and the extreme of the output $\left(\mathrm{ET}_{0}\right)$ of hydrological models at both daily and monthly scales are analyzed. It shows clearly that it is not reliable to use the extremes of the input to linearly determine the extreme of the output. In some cases deducing a minimum at monthly scale is safer than deducing a maximum at daily scale. To predict the extremes, it is especially important to consider both the quantity and the occurrence of the extremes, which may not be well related to the same variable. SD and $U_{2}$ are two of the highest contributors to $\mathrm{ET}_{0}$ trend. The occurrence of the extreme of $U_{2}$ is not in consistent with the occurrence of the $\mathrm{ET}_{0}$ extreme, whereas the occurrence of SD's maximum is mostly in agreement with the occurrence of $\mathrm{ET}_{0}$. The main driver of $\mathrm{SD}$ in this case study is a good indicator to predict the extreme of $\mathrm{ET}_{0}$. It reveals that the more linear the relationship between the input and output is, the easier and more accurately the model can be used to find the footprint of the hydrological signatures.

\section{References}

Allen, R. G., Pereira, L. S., Raes, D., and Smith, M.: Crop evapotranspiration-Guidelines for computing crop water requirements-FAO Irrigation and drainage paper 56, FAO, Rome, 300, 6541, 1998.

Blöschl, G., Sivapalan, M., and Wagener, T. (Eds.): Runoff prediction in ungauged basins: Synthesis across processes places and scales, Cambridge University Press, Britain, 2013.

IPCC 2013: Climate Change 2013, The Physical Science Basis, Summary for Policymakers, in: Working Group I Contribution to the Fifth Assessment Report of the Intergovernmental Panel on Climate Change, edited by: Stocker, T. F., Qin, D., Plattner, G.-K., Tignor, M., Allen, S. K., Boschung, J., Nauels, A., Xia, Y., Bex, V., and Midgley, P. M., the IPCC, Switzerland, p. 18, 2013.

Liu, S. X., Mo, X. G., Xia, J., Liu, C. M., and Ji, L. N.: The uncertainty analysis of the wetted perimeter method via axis scaling for setting minimum ecological in-stream flow requirements, Publ. No. 322, IAHS, Wallingford, UK, 193-198. 2008.

Zhang, S. H., Liu, S. X., Mo, X. G., Shu, C., Sun, Y., and Zhang, C.: Assessing the impact of Climate Change on reference evapotranspiration in Aksu river basin, J. Geogr. Sci., 65, 1363-1370, 2010.
Acknowledgements. This work is financially supported by the project of Chinese National Natural Science Foundation (31171451), "135" Key Project for the Strategic Science Plan in IGSNRR, CAS and the 973 project (2012CB957802). 